\section{El estado del arte de la movilidad del transporte en la vida urbana en ciudades latinoamericanas}

Gerardo Alonso Romero

Centro Panamericano de Estudios Superiores, México.

\author{
Diosey Ramón Lugo-Morín \\ Centro Panamericano de Estudios Superiores, México.
}

\title{
Resumen
}

En un análisis documental con enfoque cualitativo, se muestra el estado del arte de la movilidad por medio de sus manifestaciones en el ámbito territorial, identificando el desafío que representa para la vida urbana contemporánea en Latinoamérica. Se reconoce la relación entre movilidad y sostenibilidad como elemento imprescindible de supervivencia para las ciudades actuales, y la necesidad de una evaluación ambiental estratégica a través de un modelo de umbrales ambientales. Se analiza su influencia sobre la economía como principal componente de la demanda de transporte y su impacto en el planeamiento urbano, principalmente de las externalidades. La congestión se aborda como contraparte, y se analizan su origen, causas, problemas comunes en Latinoamérica, la contribución del transporte urbano y sus efectos en la sociedad. Finalmente se revisan las soluciones para mejorarla mediante ejemplos representativos, y la aplicación de políticas públicas con tres enfoques principales: la calidad de vida de los ciudadanos, la eficiencia, y la sostenibilidad. Se reconocen resultados tanto exitosos como fallidos. A través de la identificación de sus elementos configuradores, resulta un panorama que precisa la necesidad de incorporar estos conceptos al medir la calidad de vida de las personas.

\section{The state of the art of transport mobility in urban life in Latin American cities}

Abstract
By a documentary analysis with a qualitative approach, the state of the art of mobility
is shown through its manifestations in the territorial scope, identifying the challenge it

Palabras clave

Migración Políticas Públicas Transporte Público Infraestructura Territorio 
represents for contemporary urban life in Latin America. It recognizes the relationship between mobility and sustainability as an essential element of survival for present-day cities, and the need for a strategic environmental assessment through a model of environmental thresholds. Its influence on the economy is analyzed as a main component of the demand of transport and its impact in the urban planning, mainly of the externalities. Congestion is addressed as a counterpart, and its origin, causes, common problems in Latin America, the contribution of urban transport and their effects on society are analyzed. Finally, solutions are reviewed to improve it through representative examples, and the implementation of public policies with three main approaches: citizen's quality of life, efficiency, and sustainability. Both successful and failed results are recognized. Through the identification of its configurator elements, it is a panorama that specifies the need to incorporate these concepts in measuring the quality of life of people.

\section{Introducción}

El concepto de movilidad va más allá de los desplazamientos físicos de un lugar a otro (Korstanje, 2013), sin éste no puede entenderse nuestra realidad actual, pues constituye el mayor desafío para la vida urbana contemporánea (Cabrera-Arana, VelásquezOsorio, Orozco-Arbeláez, 2015).

En el presente trabajo se hace un acercamiento al estado del arte de la movilidad urbana en un breve análisis general de un tema por demás complejo, por medio de sus diferentes manifestaciones en el ámbito territorial, es a través de su estudio que se busca dejar preparado el camino para determinar su impacto en la calidad de vida de los habitantes de un centro urbano. Para ello se realiza un análisis documental, con enfoque cualitativo de los diversos estudios sobre el tema.

En la primera parte se hace un breve acercamiento al concepto de movilidad y se aborda el enfoque de los desplazamientos de las personas y sus repercusiones en la realidad de las sociedades actuales. La segunda parte trata de la migración como una de las expresiones de movilidad más notables entre sociedades y naciones, el impacto en la vida de los migrantes, en los lugares que dejan así como en los que llegan a residir (Cruz-Zúñiga, 2016). Se identifica el panorama global de los flujos migratorios internacionales, y su contraste con la dinámica al interior de los países (Castles, 2014). Se aborda ligeramente el concepto de frontera y su relación con la movilidad humana contemporánea (Zapata-Barrero, 2012). A continuación se hace referencia a las causas generales de la migración, con el fenómeno de aprendizaje que conlleva a través de las prácticas sociales y de los territorios (Reyes, Martínez, 2015).

En la tercera parte se busca interiorizar en la movilidad como parte de la vida urbana, haciendo referencia a su importancia como componente fundamental de la cultura y como factor de desarrollo político, económico y sociocultural por sí mismo (Lange, 2011), la clasificación de los espacios sociales de transformación (Vivas y Ribera, 2007), así como su influencia en los modos de vida de los habitantes (Lange, 2011; Vich, Delclós y Miralles-Guasch, 2015), para llegar a la identificación de los roles que juega en el ámbito urbano y territorial.

La cuarta parte aborda como un concepto imprescindible para la supervivencia de las ciudades actuales: la relación entre movilidad y sostenibilidad, resaltando los desafíos que representan tanto su control en lo individual como la reducción de las desigualdades para la accesibilidad al transporte (Mignot et al., 2010). Se observan la necesidad y las ventajas de integrar de manera óptima una evaluación ambiental, mediante la evaluación ambiental estratégica utilizando un modelo de umbrales (Soria y Valenzuela, 2015).
Palavras-chave

Migração Políticas públicas Transporte público Infraestrutura Território 
Se aborda también el mecanismo a través del cual la movilidad tiene influencia sobre la economía, que explica el origen de la demanda de transporte (Islas, Rivera y Torres, 2002) al reflejar las características de la oferta - como velocidades o nivel de servicio - y variables externas - urbanísticas y socio demográficas - lo que impacta decisivamente sobre el planeamiento urbano con el que se define la infraestructura física de las ciudades.

En cualquier análisis de movilidad, debe incluirse de manera esencial el fenómeno de congestión como la contraparte natural por el incremento en la demanda de la infraestructura disponible, cuyo impacto llega a representar hasta el 3,5\% del PIB de Latinoamérica (Thomson y Bull, 2002; Lupano y Sánchez, 2009). Se enuncian sus causas técnicas, de educación vial y no menos importante, la inadecuada gestión de las autoridades competentes; sus efectos que se manifiestan en una menor capacidad vial que la que corresponde con sus características geométricas; sus consecuencias recaen en costos económicos mayores y afectación en la calidad de vida de los habitantes, lo que contribuye también a la inequidad social (Thomson y Bull, 2002).

La siguiente parte muestra diferentes soluciones de movilidad experimentadas en ciudades que sirven de ejemplo de casos exitosos, en donde se mantiene el binomio de dimensiones ambiental y social (Mignot et al., 2010). Destaca el enfoque de sustentabilidad (Lupano y Sánchez, 2009), pero también se identifican otros con los que se llegó a resultados negativos, los que tienen como factor común el aplicar dos tipos de soluciones simultáneas: la ampliación de la infraestructura vial y la ampliación o mejora del transporte masivo, con la consecuencia de que se potencia la congestión futura al tiempo que se entorpecen mutuamente los automóviles particulares con el transporte público. De los ejemplos se pueden extraer innovaciones técnicas que en resumen facilitan la racionalización del espacio vial urbano (Lupano y Sánchez, 2009). También se hace mención breve del concepto de teletrabajo, sin que hasta el momento se tengan conclusiones que permitan determinar su impacto como alternativa sustentable, quedando como una propuesta positiva en los planes de movilidad (Verano, Suárez y Sosa, 2014). Se concluye que la congestión es inevitable (Thomson y Bull, 2002) siendo mejor controlarla dentro de ciertos límites, dado el alto costo de pretender eliminarla, lo que conllevaría entre otras medidas a mayor ampliación de la capacidad vial, desvío de usuarios a otras vías o modos de viaje, además de una eventual supresión de viajes dada por medidas restrictivas a los automovilistas (Bull, 2003).

Finalmente se exploran las políticas públicas encaminadas a ofrecer soluciones de movilidad, lo cual es uno de los Objetivos Desarrollo del Milenio establecidos por la ONU (Pardo, 2010). Tienen tres enfoques principales: la calidad de vida de los ciudadanos, la eficiencia, y la sostenibilidad (Lupano y Sánchez, 2009; Pardo, 2010). Su diseño debe considerar las externalidades en el análisis económico. Tampoco deben quedar fuera las soluciones para los sectores más desprotegidos, como los ancianos, mujeres embarazadas o personas con capacidades diferentes. Las experiencias exitosas se resumen en: desconcentración de las decisiones mediante autoridades locales autónomas con capacidad de acción y competencia plena; enfoques integrales que incluyen aspectos ambientales y de participación social; recursos fiscales asignados a la infraestructura y transporte, incluyendo subsidios cruzados que permiten la progresiva expansión hacia tarifas intermodales; y cooperación público - privada, a pesar de que sus esquemas normativos requieren ser perfeccionados (Lupano y Sánchez, 2009). Todo lo anterior con el monitoreo de los patrones de movilidad para asegurar la sustentabilidad de las ciudades (Poelman y Dijkstra, 2015).

Derivado de este análisis se pueden identificar los elementos configuradores de la movilidad que permiten obtener las propuestas técnicas traducidas en políticas públicas, enfocadas a mejorar la calidad de vida de los habitantes con visión de sostenibilidad. 


\section{El concepto de movilidad}

La movilidad es un concepto que tiene diversas acepciones de acuerdo con el área del conocimiento en la que se estudia, de modo que es objeto de interés para diversas disciplinas, como la matemática, la física, las ingenierías, la ecología, la economía, la antropología, geografía, historia y sociología, la política, la planeación y el urbanismo, la psicología, el derecho, la ergonomía o la salud pública, también es el mayor desafío para la vida urbana contemporánea (Cabrera-Arana, Velásquez-Osorio, Orozco-Arbeláez, 2015). Sheller y Urry (2006) definen el nuevo paradigma de la movilidad a partir de estudios en antropología, cultura, geografía, migración, ciencia y tecnología, turismo y transporte, y sociología, que Incluye los movimientos de imágenes e información en medios locales y globales, las telecomunicaciones personales y las redes virtuales. Por otro lado, la movilidad social es "toda transición de un individuo, objeto o valor social \cualquier cosa que haya sido modificada por la actividad humana $\nabla$ de una posición a otra" (Pérez, 2015:150).

Nuestra realidad actual no puede entenderse sin el concepto de movilidad, que va más allá de los desplazamientos físicos de un lugar a otro, trasciende la dicotomía entre la investigación del transporte y las investigaciones sociales al relacionarlas en diferentes formas dando lugar a complejos patrones de experiencias sociales a través de comunicaciones en la distancia (Sheller y Urry, 2006). Implica la revalorización de espacios dándoles sentido de lugar; la alteración de nuestros tiempos de recreación y descanso, el intento de extender la vida de las personas por la vinculación de todos los lugares en virtud de una red de conexiones que se extiende creando zonas de conectividad por un lado, y zonas de desconexión y exclusión por el otro (Marcu, 2016); la notable aceleración de los tiempos de espera y; el surgimiento de un nuevo ciudadano-móvil, creativo, innovador y coproductor de movilidad (Korstanje, 2013). En otras palabras, la movilidad es una posibilidad, una causa, una necesidad y una fortaleza del hombre moderno y destruye la noción de sedentarismo típicamente presente en muchos estudios de geografía, antropología y sociología (Sheller y Urry, 2006).

En términos arquitectónicos, la propuesta contemporánea busca crear espacios para transitar o estar de paso, formando "ambientes de la movilidad" (Vivas y Ribera, 2007). Como resultado de la innovación tecnológica, ahora los viajes son más confortables y surge el concepto de ciudadano móvil para el que existe un excedente de tiempo que aprovecha involucrando sus preferencias personales en la experiencia de viajar, y el tiempo clásico de espera ahora puede ser aprovechado (Korstanje, M. 2013).

La nueva economía mundial genera movilidad de capital y del trabajo, que a la vez crean nuevos espacios de producción y consumo (Cruz-Zúñiga, 2016). En el nuevo orden territorial, el modelo de exportación nacional se reproduce a escalas menores del territorio, al diversificarse los servicios y segmentarse los mercados (Jordán et al., 2003).

El transnacionalismo es definido como el espacio en el cual los migrantes practican la movilidad, el siglo XXI es la era de la movilidad, fluidez, apertura y conectividad en el cual ha cambiado el concepto de frontera: de línea divisoria a conexiones del interior con el exterior, de modo que la movilidad transfronteriza es el reflejo de las políticas y dinámicas que incluyen aspectos como la seguridad a escala global (Marcu, 2016).

La pobreza es una manifestación de la segregación residencial, así que cuando se supera se logra la movilidad social ascendente, para ello se requiere que los avances en salud, educación empleo o vivienda se acompañen con proyectos urbanos hacia la integración territorial de la ciudad (Jordán et al.,2003). Por el contrario, la movilidad descendente se observa cuando las personas ingresan al segmento de pobreza afectados por las crisis económicas. La relación entre movilidad y desigualdad no solo se manifiesta en 


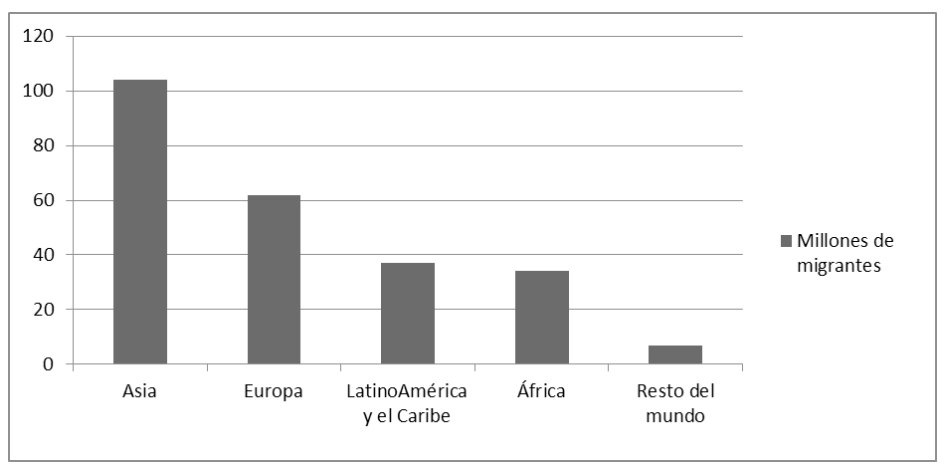

función del desplazamiento, sino también por el "posicionamiento, los atributos, la disposición, las posibilidades y las atribuciones propias de quien realiza el movimiento" (Pérez, 2015:153)

\section{La migración como agente de movilidad}

La migración es uno de los agentes de movilidad más importantes entre sociedades y naciones. Ha sido una constante a lo largo de la historia y tiene repercusiones para los migrantes, los lugares que dejan y los que los acogen. Derivados de la globalización, los movimientos migratorios actuales no tienen precedentes (Cruz-Zúñiga, 2016). En términos globales a nivel internacional el incremento ha sido casi constante desde 1990 a 2010 (de 2,9\% a 3,1\% respectivamente de migrantes con respecto a la población mundial), pero los países desarrollados reciben a la mayoría de los migrantes internacionales - $60 \%$ del total en 2010 , lo que representa el $10 \%$ de su población, en contraste con el 1,5\% de la población de países en desarrollo - (Castles, 2014). Aproximadamente el 50\% de los migrantes internacionales residen en los países con mayor urbanización e ingresos: Australia, Canadá, Estados Unidos, Francia, Alemania, España, Reino Unido, Federación Rusa, Arabia Saudita y Emiratos Árabes Unidos (Cruz-Zúñiga, 2016). El reporte de las Naciones Unidas sobre Migración Internacional 2015 (Naciones Unidas, 2016) muestra que de los 244 millones de migrantes internacionales en el mundo, 104 millones son asiáticos, 62 millones europeos, 37 millones nacieron en Latinoamérica y el Caribe y 34 millones en África (figura 1). Los países con mayor emigración en millones de personas son India (16), México (12), Federación Rusa (11), China (10), Bangladesh (7), Paquistán y Ucrania ( 6 cada uno). El crecimiento de población en Norteamérica entre 2000 y 2015 fue debido en $42 \%$ a los migrantes, y en Oceanía en 32\%.

En Latinoamérica la mayoría de las metrópolis con más de 5 millones de habitantes presenta un saldo migratorio negativo, por factores múltiples entre los que destacan las deseconomías de escala y el cambio de inversiones públicas hacia otras áreas, provocando que quien no puede adquirir periódicamente los artículos necesarios termine por irse, y problemas urbanos como la inseguridad pública, congestión vial y contaminación (Da Cunha, 2009). Entonces, la migración en última instancia es consecuencia de la inmovilidad en el lugar de origen (Santos, 1995). En el caso de los refugiados contrasta la proporción, pues cerca del $85 \%$ vive en países en desarrollo. En un mayor acercamiento se observa que la proporción de migrantes de países en desarrollo hacia países desarrollados ha aumentado con mucha mayor velocidad desde fines de la década de 1990, por razones no solamente económicas, sino familiares, de educación, estilo de vida o por migración forzada. La migración interna también es digna de estudio, a nivel mundial es mucho más numerosa que la internacional (Cruz-Zúñiga, 2016) y destaca en países de gran población como China, India, Brasil, Indonesia o Nigeria. Aunque es imposible cuantificarla con precisión, el Programa de las Naciones Unidas para el Desarrollo la calculó en 740 millones de personas en el año 2009 (Castles, 2014). Por ejemplo, en China en 2003 el total de trabajadores rurales migrantes a las ciudades fue
Figura 1. Migración Internacional 2015. Fuente: Reporte de las Naciones Unidas sobre Migración Internacional, 2015. 
de 114 millones (Shaohua, 2005). En México la migración interna fue de 7,6\% entre 2005 y 2010, se destaca que entre las ciudades mayores a 500.000 habitantes solo León tiene una tasa menor a $5 \%$, pero hay ciudades medianas y grandes, en donde esa tasa es de $10 \%$ a $15 \%$, y la inmigración es muy variable, entre $6 \%$ hasta $27,87 \%$ en el caso de la zona metropolitana de Cancún (Cuadro 1).

Cuadro 1. Tasas de migración en ciudades mayores a 500,000 habitantes. Fuente: elaboración propia a partir de CEPAL, base de datos de migración interna en América Latina y el Caribe https://www.cepal.org/ celade/migracion/migracion_interna/default-ciudades.html

\begin{tabular}{|c|c|c|c|c|c|c|}
\hline \begin{tabular}{|l|} 
Tasa de \\
emigración \\
(\%)
\end{tabular} & $\begin{array}{l}\text { Rango de población } \\
\text { (habitantes) }\end{array}$ & Zona urbana & $\begin{array}{l}\text { Población } \\
\text { residente en } \\
2010\end{array}$ & $\begin{array}{l}\text { Población } \\
\text { residente en } \\
2005\end{array}$ & $\begin{array}{c}\text { Tasa de } \\
\text { inmigración }\end{array}$ & $\begin{array}{c}\text { Tasa de } \\
\text { emigración }\end{array}$ \\
\hline$<5$ & 1.250.000-1.499.999 & ZM de León & 1.414 .383 & 1.408 .442 & 4,78 & 3,94 \\
\hline \multirow[t]{22}{*}{$5-10$} & \multirow[t]{7}{*}{ 500.000-749.999 } & Durango. Victoria de & 508.154 & 513.440 & 6,40 & 8,46 \\
\hline & & Hermosillo & 684.354 & 671.559 & 10,45 & 6,68 \\
\hline & & ZM de Morelia & 715.101 & 708.828 & 10,92 & 9,16 \\
\hline & & ZM de Reynosa y Río Bravo & 618.234 & 587.708 & 19,20 & 9,08 \\
\hline & & ZM de Saltillo & 721.988 & 714.971 & 7,92 & 5,96 \\
\hline & & ZM de Villa Hermosa & 674.566 & 671.863 & 8,88 & 8,08 \\
\hline & & ZM de Xalapa Enriquez & 596.870 & 589.618 & 10,51 & 8,07 \\
\hline & \multirow[t]{9}{*}{ 750.000-999.999 } & Culiacan Rosales & 760.661 & 768.430 & 6,17 & 8,20 \\
\hline & & Mexicali & 832.839 & 827.908 & 8,24 & 7,05 \\
\hline & & San Luis Potosí & 930.848 & 927.047 & 7,65 & 6,84 \\
\hline & & ZM de Aguascalientes & 818.894 & 797.952 & 11,17 & 5,98 \\
\hline & & ZM de Chihuahua & 762.300 & 762.509 & 6,71 & 6,76 \\
\hline & & ZM de Cuernavaca & 784.269 & 766.322 & 13,50 & 8,87 \\
\hline & & ZM de Mérida & 872.752 & 854.929 & 9,99 & 5,86 \\
\hline & & ZM de Querétaro & 968.895 & 932.005 & 15,38 & 7,62 \\
\hline & & ZM de Tampico & 765.126 & 763.965 & 8,69 & 8,39 \\
\hline & 1.000.000-1.249.999 & ZM La laguna (Torreón) & 1.083 .702 & 1.076 .539 & 6,40 & 5,07 \\
\hline & \begin{tabular}{|l}
$1.500 .000-1.749 .999$ \\
\end{tabular} & ZM de Toluca & 1.643 .562 & 1.603 .429 & 11,08 & 6,14 \\
\hline & 2.250.000-2.499.999 & $\begin{array}{l}\text { ZM de Puebla de Zaragoza. } \\
\text { Heroica-Tlaxcala }\end{array}$ & 2.389 .410 & 2.392 .253 & 6,45 & 6,69 \\
\hline & 3.500.000-3.749.999 & ZM de Monterrey & 3.604 .246 & 3.602 .576 & 6,74 & 6,64 \\
\hline & 3.750.000-3.999.999 & ZM de Guadalajara & 3.911 .469 & 3.909 .362 & 6,32 & 6,21 \\
\hline & $>18.000 .000$ & $\begin{array}{l}\text { ZM del Valle de México } \\
\text { (Ciudad de México) }\end{array}$ & 18.055 .151 & 18.204 .169 & 4,16 & 5,81 \\
\hline \multirow[t]{7}{*}{$10-15$} & \multirow[t]{4}{*}{ 500.000-749.999 } & Veracruz. Heroica & 730.346 & 746.242 & 10,21 & 14,51 \\
\hline & & ZM de Cancún & 579.190 & 542.240 & 27,87 & 14,69 \\
\hline & & ZM de Oaxaca & 526.589 & 538.849 & 10,35 & 14,95 \\
\hline & & ZM de Tuxtla Gutiérrez & 575.213 & 576.019 & 9,80 & 10,08 \\
\hline & 750.000-999.999 & ZM de Acapulco & 767.948 & 785.359 & 6,02 & 10,50 \\
\hline & 1.000.000-1.249.999 & Ciudad Juárez & 1.164 .227 & 1.191 .296 & 6,40 & 10,99 \\
\hline & 1.250.000-1.499.999 & ZM de Tijuana & 1.497 .494 & 1.490 .568 & 13,49 & 12,57 \\
\hline
\end{tabular}

En las ciudades pequeñas (de 20.000 a 100.000 habitantes) se llegan a tener tasas mucho mayores, pues hay nueve ciudades con tasas de emigración mayores a 20\%, llegando a 43,09\% en Francisco Escárcega (Cuadro 2). 
Cuadro 2. Tasas de migración mayores a 20\%en ciudades de 20.000 a 100.000 habitantes. Fuente: elaboración propia a partir de CEPAL, base de datos de migración interna en América Latina y el Caribe https://www.cepal. org/celade/migracion/migracion_interna/default-ciudades.html

\begin{tabular}{|l|l|c|c|c|c|}
\hline $\begin{array}{l}\text { Tasa de } \\
\text { emigración } \\
(\mathbf{( \% )}\end{array}$ & Tasa de emigración (\%)/Ciudad & $\begin{array}{c}\text { Población } \\
\text { residente en } \\
\mathbf{2 0 1 0}\end{array}$ & $\begin{array}{c}\text { Población } \\
\text { residente en } \\
\mathbf{2 0 0 5}\end{array}$ & $\begin{array}{c}\text { Tasa de } \\
\text { inmigración }\end{array}$ & $\begin{array}{c}\text { Tasa de } \\
\text { emigración }\end{array}$ \\
\hline $\mathbf{2 0 - 2 5}$ & Agua Dulce & 41.342 & 44.654 & 5,07 & 20,48 \\
\hline & Progreso & 48.524 & 51.526 & 8,39 & 20,39 \\
\hline & Puerto Peñasco & 49.452 & 48.456 & 26,15 & 22,08 \\
\hline & Tenosique de Pino Suarez & 53.044 & 56.449 & 8,91 & 21,35 \\
\hline & Tres Valles & 40.410 & 43.025 & 10,34 & 22,88 \\
\hline $25-30$ & Chapala & 41.913 & 46.715 & 6,54 & 28,22 \\
\hline $35-40$ & Matias Romero & 34.780 & 38.219 & 6,66 & 25,50 \\
\hline $40-45$ & Jocotitlán & 53.479 & 60.901 & 9,85 & 35,81 \\
\hline
\end{tabular}

La creciente movilidad internacional también ha puesto de relieve el concepto y la categoría de frontera, cuyo estudio ahora debe trascender el enfoque tradicional de su relación exclusiva con el territorio, para atender la gestión de la movilidad humana en permanente cambio, pues se debe incluir el sentido físico territorial tanto como el sentido simbólico en todos los contextos posibles y hasta el vínculo entre frontera y soberanía es hoy diferente a como se entendía hace algunas décadas (Zapata-Barrero, 2012).

La migración internacional es impulsada principalmente por la integración económica global, pero deben también considerarse para su estudio factores como la globalización neoliberal y transformación social, la desigualdad, seguridad estatal y seguridad humana, tecnología, demanda de mano de obra, cambios demográficos, razones políticas, el derecho y la gobernanza, la dinámica social de la migración, sin dejar de lado el papel de las personas que viven como intermediarios de la migración (Castles, 2014:238; Cruz-Zúñiga, 2016). Ante esta nueva realidad, se presenta la "paradoja liberal" (CruzZúñiga, 2016:4) que se refiere a que por un lado el sistema mundial promueve la libre circulación de capitales, bienes y mercancías, pero por el otro también establece más medidas de control para el paso de las personas, de modo que la migración es un proceso cada vez más complejo y multidireccional, lo que representa un reto para la convivencia cotidiana, especialmente en el caso de la migración forzada o no deseada (Cruz-Zúñiga, 2016).

Por otra parte, el concepto de "aprendizaje de la movilidad" (Marcu, 2016:4) ha sido poco estudiado en la literatura, para entender sus características es necesario incluir las percepciones de las personas en el ámbito transfronterizo, en sus experiencias y su toma de conciencia, pues se transforma no solo la vida de los migrantes, sino también de los no migrantes y los lugares físicos tanto de origen como de llegada, entre los cuales construyen vínculos sociales (Reyes, Martínez, 2015). Así, la movilidad crea una cultura en la relación entre migración internacional y sujeto migrante a través de las prácticas y representaciones de las personas con las que se apropian de los nuevos territorios, de modo que se establece una "circulación de territorios (espacio reticular)" y una "territorialización” (Reyes, Martínez, 2015:122,125) en los lugares de inmigración.

\section{La movilidad en la vida urbana}

Tradicionalmente se ha estudiado la evolución urbana con el enfoque de la economía, sociología y geografía urbana, ligada con modelos cuantitativos que la 
relacionan con factores de localización industrial y transporte, pero están surgiendo nuevos ambientes suburbanos que se desarrollan bajo otras variables como las tecnologías de la comunicación, los patrones de movilidad, la planificación territorial, el desarrollo inmobiliario, o la disposición de zonas y riesgos naturales, lo que obliga a una nueva comprensión cuantitativa del crecimiento de las ciudades (Rojas, et al. 2014).

Desde un enfoque territorial, la movilidad queda descrita de manera tal que se puede identificar claramente su influencia en la calidad de vida de las personas: es la cualidad por la que las personas y bienes pueden ser desplazadas de modo digno, oportuno, confiable y económico, para atender las necesidades básicas de vivienda, educación y salud, mediante una adecuada infraestructura de transporte urbano (Lupano y Sánchez, 2009). Una de las problemáticas más importantes de la vida urbana contemporánea es la movilidad urbana (Lange, 2011), que requiere de una política particular de transporte (Jordán, et al., 2003). Entre los factores que la afectan, se identifican: accesibilidad regional, densidad, mezcla de usos del suelo, centralización, conectividad de carreteras y caminos, diseño de carreteras, condiciones de transporte peatonal y en bicicleta, calidad del transporte público, disponibilidad y manejo de estacionamientos, diseño de los sitios, administración de la movilidad y programas integrados de crecimiento inteligente, cada uno de ellos los afecta de modo parcial, pero sus efectos son sinérgicos (Litman, 2017). En cuanto al crecimiento de los tráficos, el impacto más grande se produce en los grandes corredores de transporte así como en las grandes metrópolis (Mignot, D. et al., 2010), pero es de resaltar que la sociología urbana tradicional no consideró el tremendo impacto del automóvil en el cambio de los hábitos de los habitantes (Sheller y Urry, 2006), lo que se observa desde los años ochenta en que Latinoamérica experimenta un patrón de asentamiento de la población con el que ya alcanzó los porcentajes de urbanización de Europa y Oceanía (da Cunha, 2009). Con ello, la movilidad es hoy un componente fundamental de la cultura urbana, ya no solo por su función de brindar accesibilidad entre las diferentes áreas de la ciudad, sino principalmente como factor de desarrollo político, económico y sociocultural por sí mismo, que aparece en el moderno modelo de "ciudad global" (Lange, 2011: 89) como un recurso para la consolidación y equilibrio entre centralidad y movilidad de los grandes centros urbanos para su organización, funcionamiento y expansión (Lange, 2011).

Las movilidades crean nuevas formas de vida en diferentes tipos de espacios sociales, así se tiene que: las estaciones, los hoteles, las autopistas y todos los espacios de servicios y ocio, se identifican como lugares del "movimiento intermitente"; los "corredores urbanos" son las trayectorias donde el tránsito es fácil; los "espacios de transición espacial" existen donde se potencia la concentración de personas en la ciudad tecnológica global; "espacios trayecto" de desplazamiento son donde se mezclan los espacios físicos y los virtuales; los "tubos espaciales" son ejes y radios que forman una red de movimientos rápidos (Sheller y Urry, 2006; Vivas y Ribera, 2007).

Es en estos espacios en donde se producen las principales transformaciones sociales y urbanas (Vivas y Ribera, 2007). Existe un campo de estudio de las ciencias sociales acerca de la influencia de las transformaciones generadas por la movilidad urbana en los modos de vida de los habitantes de las ciudades, en el que hay opiniones diversas, desde las que consideran a la movilidad como parte de la libertad personal que tiene un ciudadano por la posibilidad de circular por el territorio, hasta el énfasis en los efectos que la infraestructura vial tiene en el aislamiento social entre las personas y la consecuente pérdida del espacio público como ámbito de expresión socio cultural; pasando por el enfoque de que la infraestructura provoca mayor tiempo de traslado, además de que propicia la ausencia de formas urbanas identificables por los habitantes; o bien la aparición de formas arquitectónicas posmodernas que al tiempo de surgir 


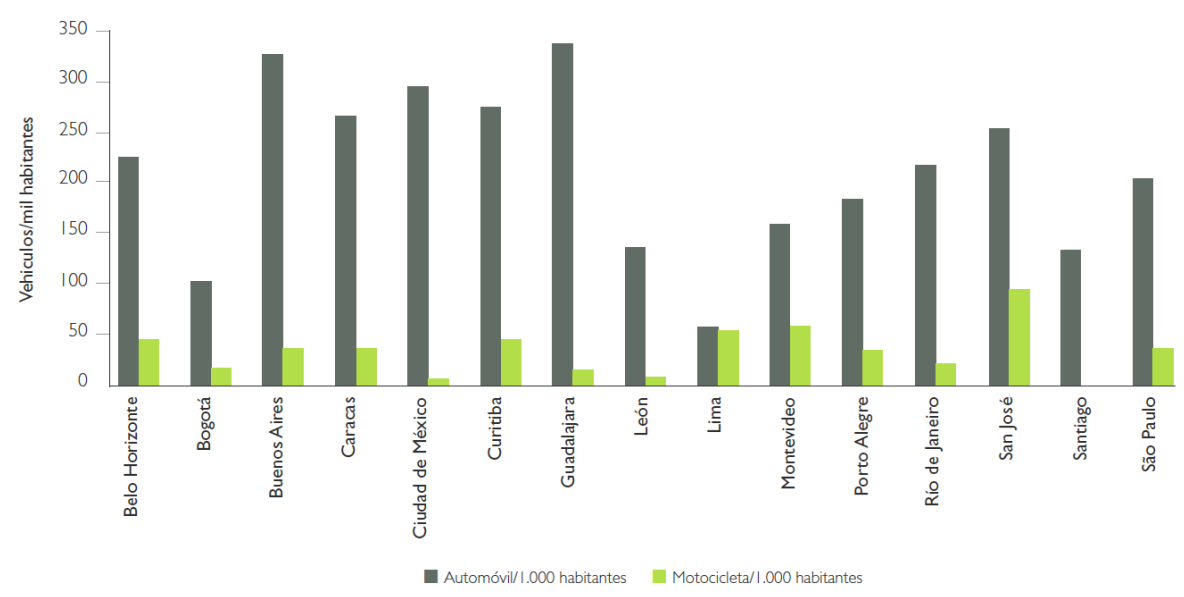

suprimen los referentes históricos perdiéndose la identidad territorial (Lange, 2011). En otras palabras, influye y es determinada por la forma y relación de los espacios urbanos (Pérez, 2015). De cualquier manera, se hace necesario estudiar los patrones de movilidad de las personas, de manera sectorizada en ámbitos de actividad o área geográfica, como es el caso de los traslados de los estudiantes de un campus universitario (Vich, Delclós, Miralles-Guasch, 2015).

Entre los roles que juega la movilidad urbana se reconocen el de cuestionar la delimitación del territorio para construir identidades culturales en los diferentes lugares; también el de acelerar la vida social urbana con el refuerzo del desarrollo tecnológico y de las comunicaciones expresados en las autopistas, líneas del metro o los vehículos motorizados, por ejemplo; otro es el de impulsar la pérdida del compromiso mutuo pues la capacidad de evitar el contacto con otros se constituye como un instrumento de poder social, y puede ser fuente de status (Sheller y Urry, 2006) aumentando el distanciamiento de las clases. Finalmente se identifica como parte de la vida diaria de los habitantes, pero se debe distinguir entre su condición como parte de los sistemas urbanos, y su cualidad como una forma de experiencia sociocultural de éstos (Lange, 2011).

La demanda de infraestructura social se incrementa especialmente en los países en desarrollo (Lupano y Sánchez, 2009), muchas economías latinoamericanas retomaron un ritmo de crecimiento notable desde el año 2003 gracias a la evolución de los ingresos de los habitantes y de los precios accesibles de los automóviles, particularmente los usados, no solo para las clases altas sino también las de ingresos medios, siendo este un fruto del avance tecnológico del siglo XX (Thomson y Bull, 2002), lo que en términos de movilidad se manifestó con el fenómeno de motorización (Figura 2), que llevó a la región a ser la de los mayores registros de daños y muertes por accidentes viales de todo el mundo (Chaparro, 2002).

El estudio de la movilidad urbana contemporánea exige el conocimiento de la infraestructura material en cuatro características: 1 . no siempre es evidente por encontrarse físicamente oculta o no visible en forma de cables y conductos; 2. el estudio de sus características físicas no es suficiente, sino que deben incluirse los arreglos, tecnologías, relaciones que forman con la ciudad; 3 . no está circunscrita a los límites de la ciudad, sino que influye y es influida por los alcances de las conexiones que genera y las condiciones geográficas de su entorno o incluso a nivel global y; 4. los riesgos de fallo o daño que implica su complejidad (Vivas y Ribera, 2007). El nuevo paradigma de la movilidad incluye seis cuerpos teóricos: I. el concepto de "tempo" urbano que considera las formas sociales, económicas e infraestructura de la ciudad pero también las "formas físicas" del habitante urbano (Sheller y Urry, 2006: 215); II. las relaciones entre los sistemas móviles de humanos y objetos que generan "geografías híbridas" (Sheller
Figura 2. Índices de motorización en ciudades seleccionadas de Latinoamérica, 2007. Fuente: Banco de Desarrollo de América Latina, Desarrollo urbano y movilidad en América Latina, 2011. 
y Urry, 2006: 215) heterogéneas; III. las espacialidades de las cosas en movimiento que cambian constantemente de configuración de paisajes y sistemas en nivel local y global; IV. la redefinición del cuerpo físico como un vehículo que percibe lugares y movimientos construyendo geografías emocionales; $\mathrm{V}$. el estudio de varias topologías sociales, especialmente las de lazos débiles que pueden generar "mundos pequeños" aparentemente desconectados y finalmente, VI. el análisis de sistemas complejos que no son ordenados ni anárquicos, en sistemas dinámicos que poseen propiedades emergentes (Sheller y Urry, 2006:216).

\section{Movilidad y sostenibilidad}

La relación entre ambos conceptos ha abordado los temas de impacto ambiental de largo plazo por el transporte urbano, con enfoques de cambio climático global, consumo de energía, destrucción de hábitats naturales y espacios verdes; también se ha enfocado a la inequidad de costos y beneficios de un sistema de transporte sustentable, o a la crisis de salud pública por obesidad relacionada con la dependencia del automóvil en ciudades, pero la dimensión social es menos explícita (Boschmann y Kwan, 2008). Las dimensiones básicas de la movilidad se refieren a que sea segura y sostenible (CabreraArana, Velásquez-Osorio, Orozco-Arbeláez, 2015) y es necesario balancear los tres objetivos de la sostenibilidad: proteger el medio ambiente al tiempo que se promueve la vitalidad económica y la equidad social explícita (Boschmann y Kwan, 2008). El que sea sostenible depende de las relaciones de proximidad y los desplazamientos no motorizados, - peatonales o en bicicleta - o en su defecto en transporte público (Cardozo, Gutiérrez, y García Palomares, 2010). Los desafíos para el control de la movilidad individual y la reducción de las desigualdades para la accesibilidad en espacios cada vez más segregados son más importantes en los territorios metropolitanos y constituyen un tema central de la ciudad sostenible, pues son evidentes las diferencias en las condiciones de accesibilidad a los puestos de trabajo de los no motorizados y no tanto en las personas que tienen acceso al vehículo particular (Mignot et al., 2010). No debe perderse de vista la dimensión individual en cuanto se refiere a las opciones de las personas para cumplir con sus actividades, lo que es posibilitado o limitado por el sistema de transporte, de modo que una escasa oportunidad de participación se relaciona con procesos de exclusión social por los distintos modos de transporte (Roa, Herty et al, 2013), así que la accesibilidad es un importante indicador de equidad social en las periferias urbanas de baja densidad (Muñiz et al., 2016)

La preferencia de uso del automóvil particular sobre el transporte público tiene diversas explicaciones, entre las cuales se encuentran: la muestra de un status o condición social del dueño del vehículo, ya sea por el tipo de automóvil o por ser propietario, sobre el uso de autobús; la calidad deficiente de los autobuses en comparación con un automóvil; la saturación de los autobuses en horas pico; la sensación de seguridad en el automóvil ante las conductas temerarias de algunos operadores de autobuses o ante la posibilidad de ser víctima de la delincuencia a bordo de uno de éstos. Por otro lado dicha preferencia se convierte en un problema en las horas pico al saturarse las vialidades, sin embargo no son muchos los automovilistas que opten por el transporte público. En general, la preferencia de uso del automóvil es muy alta en las ciudades latinoamericanas, mientras que sucede lo contrario en Europa o Estados Unidos. Esto redunda en cada vez más bajas velocidades de circulación, y las redes viales urbanas latinoamericanas ya están operando muy cerca de su capacidad (Thomson y Bull, 2002).

Las formas urbanas tienen tres grandes características: distribución o extensión urbana, concentración y segregación. Cada una de éstas puede tener efectos contradictorios, de modo que no se puede establecer que una forma monocéntrica permite trayectos más o menos cortos que una policéntrica y la forma no es suficiente para garantizar un 
modelo de ciudad más sostenible (Mignot et al., 2010). La sostenibilidad en un modelo de ciudad se ha tratado de determinar bajo dos enfoques: ciudad autosuficiente y ciudad compacta, pero no es posible definir a priori cuál es el impacto de la densidad sobre el consumo de energía y las emisiones de gases de efecto invernadero (Rojas, 2016). Las variables de forma y estructura urbana ejercen un bajo impacto en la huella ecológica, siendo más bien las diferencias de renta per cápita las que lo determinan (Rojas, 2016). En correspondencia con estas ideas, se requieren nuevos enfoques que lleven a resultados más válidos en las decisiones sobre movilidad urbana, donde se incluya una óptima integración ambiental, lo que puede lograrse a través de la evaluación ambiental estratégica, que trasciende sobre la evaluación del impacto ambiental, en cuanto que esta última conlleva a modelos de caja negra como los análisis de costo beneficio o análisis de vulnerabilidad ambiental, pues en ellos tienen gran influencia las externalidades que afectan a toda la ciudad (Soria y Valenzuela, 2015). A través de un modelo de umbrales ambientales (Cuadro 3) que se basa en técnicas de estimación de frontera para distinguir procesos eficientes de ineficientes, se incluye el análisis de cuatro dimensiones relacionadas entre sí: a) rendimiento ambiental; b) umbrales ambientales; c) enfoque integrado y; d) ayuda a la decisión/planificación. Multitud de investigaciones que buscan definir con exactitud qué tipo de relación existe entre la estructura urbana y patrón de viaje, no están enfocados en el nivel operativo, de modo que se enfrentan a problemas de aplicabilidad, sencillez y flexibilidad. Por lo tanto, la propuesta de los umbrales ambientales se contextualiza sobre unidades espaciales denominadas entornos de movilidad, definidas a nivel operativo con base en los factores de estructura urbana y patrón de viaje. Con ello es posible obtener información sobre las cuatro dimensiones de la movilidad: urbanística, ambiental, socio económica y modal (Soria y Valenzuela, 2015). El enfoque de indicadores de sostenibilidad que propone Salado García et al. (2006) considera los patrones de movilidad, un sistema de transporte público eficaz y espacialmente equitativo y un modelo urbano caracterizado por la densidad y mezcla de usos.

Cuadro 3. Rasgos básicos del Modelo de Umbrales Ambientales propuesto por Soria y Valenzuela. Fuente: Soria y Valenzuela, 2015

\begin{tabular}{|c|c|c|}
\hline \multicolumn{2}{|c|}{$\begin{array}{l}\text { Planteamiento proactivo } \\
\text { Dimensiones }\end{array}$} & "Modelo de umbrales ambientales. MUA" \\
\hline \multirow{7}{*}{$\begin{array}{l}\text { Fases de } \\
\text { análisis y } \\
\text { diagnóstico } \\
\text { ambiental }\end{array}$} & \multirow[t]{3}{*}{$\begin{array}{l}\text { Rendimiento } \\
\text { ambiental }\end{array}$} & $\begin{array}{l}\text { Entradas al sistema (uso de recursos y energía por la } \\
\text { movilidad). }\end{array}$ \\
\hline & & Salidas del sistema (emisión de residuos y ruido). \\
\hline & & Uso modal viario del corredor \\
\hline & \multirow[t]{2}{*}{$\begin{array}{l}\text { Umbrales } \\
\text { ambientales }\end{array}$} & $\begin{array}{l}\text { Umbral Crítico de Calidad (UCC). Valor óptimo de } \\
\text { rendimiento ambiental, por debajo del cual, las } \\
\text { consecuencias ambientales de la movilidad serían muy bajas } \\
\text { o nulas }\end{array}$ \\
\hline & & $\begin{array}{l}\text { Umbral Crítico de Impacto (UCI). Valor mínimo de } \\
\text { rendimiento ambiental, por encima del cual, las } \\
\text { consecuencias ambientales para el corredor serían muy } \\
\text { graves e incluso irreversibles. }\end{array}$ \\
\hline & \multirow[t]{2}{*}{$\begin{array}{l}\text { Enfoque } \\
\text { integrado }\end{array}$} & $\begin{array}{l}\text { Se utilizará el concepto de entorno de movilidad como } \\
\text { unidad espacial resultante de características de la estructura } \\
\text { urbana y del patrón de viaje }\end{array}$ \\
\hline & & $\begin{array}{l}\text { Se realizará un diagnóstico ambiental de cada alternativa con } \\
\text { base en los entornos de movilidad definidos. }\end{array}$ \\
\hline $\begin{array}{l}\text { Fase de ayuda } \\
\text { a la decisión }\end{array}$ & $\begin{array}{l}\text { Herramientas } \\
\text { de ayuda a la } \\
\text { decisión }\end{array}$ & $\begin{array}{l}\text { Se propondrán diferentes indicadores de ayuda a la decisión } \\
\text { sobre la alternativa seleccionada para optimizar su diseño } \\
\text { ambiental, con base en los resultados obtenidos en etapas } \\
\text { anteriores. }\end{array}$ \\
\hline
\end{tabular}


Actualmente se evalúa el impacto en la equidad social provocado por las tarifas de transporte público basadas en la distancia, con la propuesta del uso de sistemas de información geográfica para visualizar distancia y costo de viaje para diferentes perfiles de población y estructuras de tarifa (Farber et al., 2014). El nuevo urbanismo busca recuperar los principios de la ciudad tradicional con sus centros urbanos, apostando a que cumplen con las necesidades para una movilidad sostenible al incrementar las opciones alternativas al viaje en coche, como caminar, bicicleta o uso del transporte público (Cardozo, Gutiérrez y García Palomares, 2010).

\section{Los costos de la movilidad}

El principal mecanismo con el cual el sistema de movilidad tiene efectos sobre la economía es el cambio en los costos de transporte y movilidad asociados al crecimiento económico y a la aglomeración (Lupano y Sánchez, 2009). La movilidad es la variable que realmente explica el origen de la demanda de transporte (Islas, Rivera, Torres, 2002) reflejando el impacto de la oferta -las velocidades o nivel de servicio-, y de variables externas -urbanísticas y sociodemográficas-, que pueden tener más influencia que las internas, siendo las urbanísticas las que explican la utilización o no del transporte público (Cardozo, Gutiérrez y García Palomares, 2010). El crecimiento económico permite menores costos, favorece el aumento de la productividad y competitividad trayendo en un círculo virtuoso mayores requerimientos de transporte; en tanto que la aglomeración aumenta la productividad de los negocios, lo que es favorecido con la infraestructura del transporte al permitir la suburbanización sin comprometer el acceso a fuentes de trabajo y materias primas (Lupano y Sánchez, 2009).

Esta exigencia impacta decisivamente sobre la infraestructura física de las ciudades y se vincula directamente con el planeamiento urbano, cambiando el viejo paradigma en el que las ciudades compactas tradicionales se consideraban inferiores en calidad de diseño e impacto ambiental que las ciudades "jardín". Este cambio se ha dado por la mayor demanda de transporte motorizado individual propio de la urbanización dispersa (Lupano y Sánchez, 2009).

El estudio de los costos de la movilidad requiere identificar la participación tanto de los costos económicos privados como de los sociales, también llamados "efectos indirectos o externalidades" (Lupano y Sánchez, 2009:43), siendo en estos últimos donde se utilizan los insumos y recursos globales cuya presencia implica la necesidad de regulación pública. Las externalidades pueden ser positivas, denominándose entonces "economías de aglomeración" (Lupano y Sánchez, 2009:43) pues surgen de los beneficios extraordinarios debidos al incremento de volumen en el mercado local, esto incluye nuevas tecnologías, mayor alcance de los negocios actuales y el surgimiento de nuevas alternativas rentables, el acceso a fuentes de ahorro y financiamiento, oportunidades más abundantes de empleo, educación y cultura. Por otro lado, las externalidades negativas incluyen la limitación física del territorio que obliga a la necesidad de planes de ordenamiento urbano, incluyendo derechos de paso y movilidad; congestión del tráfico como la manifestación inmediata de la demanda de infraestructura para movilidad; contaminación ambiental; accidentalidad, con grandes costos económicos y sociales y; aspectos distributivos, pues la saturación de las vías por los automóviles particulares implica limitaciones de acceso a la movilidad urbana para los sectores sociales de menores ingresos. Mattos (2006) identifica los procesos de periurbanización y policentrización de las ciudades y los asocia al impacto simultáneo, combinado y generalizado de las nuevas tecnologías de la información, en conjunto con un explosivo aumento de la movilidad que derivaron en una ampliación territorial del campo metropolitano de externalidades. 


\section{La congestión}

Un diseño racional de movilidad requiere invariablemente el estudio de su contraparte: la congestión, pues con la nueva dinámica económica a partir de los años noventa en donde las clases de ingresos medios mejoraron su poder adquisitivo y tuvieron mayo acceso al automóvil, acompañado de factores microeconómicos favorables en conjunto con un mayor crecimiento de la población que además cambió su estructura familiar a unidades más pequeñas, aumento de la demanda de suelo urbano y por nuevos tipos de vivienda y falta de políticas estructuradas en el transporte urbano en un estado subsidiario con regulaciones débiles, se llegó a condiciones de saturación de las vías de comunicación disponibles al presentarse exceso de demanda sobre estos espacios (Mattos, 2006). Se manifiesta con más accidentes, demoras y excesos en el consumo de combustible, con el consiguiente daño ecológico, y llega a representar hasta 3,5\% del PIB regional en Latinoamérica (Thomson y Bull, 2002; Lupano y Sánchez, 2009). Como ejemplo, el Cuadro 4 muestra los costos de las externalidades en zonas metropolitanas de México.

Cuadro 4. Estimación de externalidades asociadas al uso del automóvil en zonas metropolitanas selectas de México, 2009 (millones de pesos). Fuente: Medina (2012).

\begin{tabular}{|l|c|c|c|c|c|c|c|}
\hline Zona Metropolitana & & $\begin{array}{c}\text { Cambio } \\
\text { Climático }\end{array}$ & Accidentes & Congestión & Ruido & Total & $\%$ del PIB \\
\hline Valle de México & 14,396 & 6,718 & 10,332 & 82,163 & 8,320 & 121,929 & $4.60 \%$ \\
\hline Monterrey & 2,282 & 1,065 & 5,843 & 11,485 & 1,319 & 21,994 & $2.80 \%$ \\
\hline Guadalajara & 2,795 & 1,304 & 4,970 & 10,635 & 1,615 & 21,319 & $4.70 \%$ \\
\hline Puebla - Tlaxcala & 996 & 465 & 1,317 & 1,894 & 575 & 5,247 & $1.80 \%$ \\
\hline León & 506 & 236 & 1,250 & 321 & 293 & 2,606 & $1.60 \%$ \\
\hline TOTAL & 20,975 & 9,788 & 23,712 & 106,498 & 12,122 & 173,095 & $4.00 \%$ \\
\hline
\end{tabular}

Sus efectos recaen sobre los ocupantes de los vehículos que circulan, que son los causantes, pero también a los pasajeros de los autobuses y por extensión, se ven perjudicados todos los habitantes de las ciudades por la contaminación acústica y atmosférica y el impacto negativo sobre la salud, lo que además de acarrear pérdida de eficiencia económica, perjudica su calidad de vida. La congestión amenaza la productividad y pone en peligro la sostenibilidad de la vida urbana (Thomson y Bull, 2002; Lupano y Sánchez, 2009).

Técnicamente se puede explicar la congestión como la fricción entre los vehículos en el flujo de tránsito, que hasta un cierto nivel pueden circular a una velocidad relativamente libre, determinada por las condiciones geométricas y sus restricciones normativas, pero a partir de un volumen de vehículos límite, cada uno adicional estorba el desplazamiento de los demás y comienza el fenómeno de la congestión, reduciendo paulatinamente las velocidades de circulación. En adelante, cada vehículo que ingresa sufre una demora, y aumenta la de los que ya están circulando (Thomson y Bull, 2002).

No todos los vehículos provocan la misma congestión. La equivalencia de vehículos para este análisis se determina en unidades de vehículos de pasajeros o pcu (passenger car unit), y se le da un valor unitario al automóvil. La equivalencia del resto de los vehículos es función de su influencia sobre el flujo de tránsito en comparación con el primero. Así por ejemplo, un autobús tiene un valor de 3 pcu, y un camión, 2 pcu. El valor también varía si se trata de una intersección o un tramo entre intersecciones. Pero aunque el autobús genera más congestión que el 
automóvil, también transporta más personas: si el promedio de ocupación de un autobús es 50 personas y el del automóvil de 1,5, entonces el ocupante del automóvil produce 11 veces la congestión de cada pasajero del autobús. Considerando lo anterior, la congestión se reduce al aumentar el porcentaje de viajes de autobús, sin embargo no debe perderse de vista que un número excesivo de autobuses agrava la congestión (Thomson y Bull, 2002).

Las causas se pueden resumir en: problemas de diseño y conservación de las vialidades por falta de marcas en el pavimento, anchos irregulares, paraderos de autobuses que invaden los carriles, entre otros; fallas y deterioros en el pavimento; poca educación vial, reflejada en la falta de respeto de algunos conductores que invaden carriles, adelantan fuera de límites, obstruyen la circulación para su ascenso, descenso o espera, circulan a muy baja velocidad; semáforos no coordinados e inclusive paso de coches o carretas de tracción animal; deficiente señalización vial y desconocimiento básico de la red, lo que provoca recorridos largos, innecesarios y repetitivos, y; gestión inapropiada de las autoridades competentes, muchas veces fragmentada en varias jurisdicciones y cuya capacidad institucional ha sido rebasada por la expansión de las flotas de vehículos particulares, lo que las lleva reaccionar de modo parcial. Este panorama se hace más complejo ante la influencia de los grupos organizados, como los transportistas, o los políticos que defienden determinados intereses o puntos de vista, lo que no es poco frecuente en Latinoamérica (Thomson y Bull, 2002; Lupano y Sánchez, 2009).

En cuanto al transporte urbano, las características que provocan la congestión se pueden resumir de acuerdo con Thomson y Bull (2002) en: demanda obligada por la necesidad de traslado de las personas, variable con horas punta; vías de transporte con capacidad limitada físicamente; las opciones de transporte más atractivas se obtienen en el automóvil, lo que genera más demanda de uso del espacio vial y; la ejecución de obras de infraestructura vial tiene un costo muy elevado. El problema se agrava pues los usuarios no perciben objetivamente los costos que conlleva, tanto en tiempo de traslado como en la operación de los vehículos - especialmente el combustible-, y sus decisiones de traslado las toman en función de una apreciación parcial de los costos propios, no de los costos sociales. Han llegado a la conclusión de que si por un lado los costos de la congestión son elevados, a la inversa, medidas para disminuirla con costos moderados, pueden dar beneficios netos significativos: conservadoramente estiman que aumentar $1 \mathrm{~km} / \mathrm{h}$ en promedio las velocidades de los viajes en auto y $0,5 \mathrm{~km} / \mathrm{h}$ los de transporte colectivo, implica una reducción equivalente de $0,1 \%$ del PIB en costos de operación.

Por lo anterior, es común que una red urbana en América Latina seguramente tenga una capacidad inferior a otra similar en Europa o Norteamérica (Thomson y Bull, 2002). En general, en el diagnóstico de movilidad para Latinoamérica se encuentra: urbanización desordenada, que incluye la ubicación periférica de los sectores de población de bajos ingresos, con limitaciones de movilidad y acceso a los transportes públicos; aumento explosivo del parque de automóviles privados, con creciente congestión de las redes viales, incremento en la contaminación ambiental y atmosférica además de niveles alarmantes de accidentalidad; sistemas de transporte colectivo de baja calidad y alto precio, limitando su competitividad así como sus posibilidades de constituir una alternativa aceptable; operadores públicos de sistemas de transporte con tecnología desactualizada y/o con servicios mal estructurados en relación a la demanda; operadores privados atomizados y con organización artesanal, con frecuencia compitiendo ruinosamente por el mercado; sistemas férreos (metros y ferrocarriles suburbanos) con déficits operativos crecientes y programas de inversión desfinanciados; falta de coordinación de las políticas de movilidad, con responsabilidades diferenciadas por modo de transporte y asignadas con límites difusos a distintos niveles jurisdiccionales (nacional, regional, local); aislamiento relativo de las políticas de transporte con respecto al planeamiento urbano general (Lupano y Sánchez, 2009). 
En Bogotá se identificaron los problemas puntuales que producen una congestión generalizada en la ciudad, influyendo en forma directa en el mal funcionamiento del sistema de transporte. La conclusión fue que contrario a la visión de una inadecuada infraestructura, la causa principal se debe más a deficiencias en la planificación, administración y operación del sistema vial, quedando su capacidad efectiva mucho menor que la capacidad instalada, a pesar de que el parque automotor fuera pequeño frente a la longitud de las vías (Chaparro, 2002).

Los efectos derivados de la congestión no solo se deben medir en términos de costos económicos y aumento del tiempo de traslado. Las afectaciones sociales incluyen el cambio obligado de hábitos de transporte de algunas personas, que adaptan sus horarios a los momentos de menor congestión, o el cambio de residencia a sitios cercanos de su lugar de trabajo. Otro efecto es la contaminación ambiental, acústica o atmosférica. Por lo tanto todos los habitantes sufren las consecuencias de la congestión vial. Específicamente para las personas que deben transportarse, es evidente que los efectos de la congestión recaen directamente en quienes los provocan, es decir, los automovilistas, pero también sobre los usuarios del transporte público, quienes la sufren sin ser los causantes, lo que significa un factor de inequidad social (Thomson y Bull, 2002)

\section{Soluciones de movilidad}

Los problemas de movilidad también son un reflejo de las dificultades cotidianas de índole social, económica y medio ambiental, más agudas en las áreas urbanas, de modo que solo se puede llegar a una ciudad sostenible si se conjugan la dimensión ambiental y social (Mignot et al., 2010) en el concepto de "movilidad urbana sustentable" (Lupano y Sánchez, 2009:12). Para lograrlo se requiere un nuevo enfoque de las autoridades hacia el transporte urbano, con mejor capacidad y calidad de respuesta, y previsión, lo que se debe lograr con la intervención de especialistas en el manejo del tránsito incluyendo un manejo integral entre las diferentes instituciones (Thomson y Bull, 2002), con el apoyo de herramientas tecnológicas entre las cuales destacan los sistemas de información geográfica (SIG) (Cardozo et al., 2015; Salado García et al., 2006).

Se considera que la movilidad de personas y bienes seguirá creciendo, así como la congestión, las emisiones y contaminantes relacionados; también, que las diferencias en calidad y cantidad de oportunidades entre los países en desarrollo con respecto a los desarrollados se ampliarán. Esto entre otros efectos previstos a futuro relacionados con la seguridad, costo, tecnología, equidad social y accidentalidad (Cabrera-Arana, Velásquez-Osorio, Orozco-Arbeláez, 2015). Por lo tanto, la planeación de la movilidad puede enfocarse en objetivos diversos o complementarios como: reducir la congestión, reducción en los costos de viaje y estacionamiento, disponibilidad y ahorro al consumidor, mejorar la movilidad de quienes no conducen; seguridad vial, conservación de la energía, reducción de emisiones de contaminantes, mejora de la salud pública, protección del hábitat y mejora de la calidad de vida de la comunidad. Las políticas de transporte afectan el desarrollo del uso del suelo, y a su vez las condiciones de uso del suelo afectan la actividad del transporte en una relación compleja de efectos interactivos, lo que obliga a entenderlos en lo individual para dar sustento a los objetivos estratégicos, como se muestra en el Cuadro 5 (Litman, 2017). 
Cuadro 5. Elementos que inciden en la planeación de la movilidad. Fuente: Litman (2017).

\begin{tabular}{|l|l|l|}
\hline Impactos del transporte & Factores de uso del suelo & Objetivos de la planeación \\
\hline & Accesibilidad regional & \\
\hline & Densidad & \\
\hline & mezcla de usos & Reducción de la congestión \\
\hline & Centrado & $\begin{array}{l}\text { Facilidad de uso de los caminos y } \\
\text { estacionamiento }\end{array}$ \\
\hline Cantidad de vehículos & Conectividad de caminos y calles & $\begin{array}{l}\text { Ahorros y disponibilidad para los } \\
\text { consumidores }\end{array}$ \\
\hline Recorridos de viaje & $\begin{array}{l}\text { Condiciones para transporte activo } \\
\text { (caminar y bicicleta) }\end{array}$ & $\begin{array}{l}\text { Movilidad mejorada para no } \\
\text { conductores }\end{array}$ \\
\hline Caminar & $\begin{array}{l}\text { Calidad de servicios en transporte } \\
\text { público }\end{array}$ & Seguridad en el transporte \\
\hline Andar en bicicleta & $\begin{array}{l}\text { Disponibilidad y administración de } \\
\text { estacionamientos }\end{array}$ & Ahorro de energía \\
\hline Viaje en transporte público & Diseño de sitios & $\begin{array}{l}\text { Reducción de emisiones } \\
\text { contaminantes }\end{array}$ \\
\hline $\begin{array}{l}\text { Viajes en vehículo } \\
\text { compartido }\end{array}$ & Administración de la movilidad & $\begin{array}{l}\text { Mejores condiciones de salud } \\
\text { pública }\end{array}$ \\
\hline teletrabajo & $\begin{array}{l}\text { Programas para crecimiento } \\
\text { inteligente integrado }\end{array}$ & $\begin{array}{l}\text { Objetivos de habitabilidad en } \\
\text { comunidad }\end{array}$ \\
\hline Viajes más cortos & & \\
\hline
\end{tabular}

Las soluciones a los retos que plantea la movilidad se han abordado desde diversas perspectivas: en el nivel nacional, por ejemplo, Francia ha creado el Grupo de Autoridades Responsables del Transporte, que representa a 263 Autoridades Organizadoras de Transporte Urbano con el propósito de promover los transportes públicos ofreciendo a sus miembros asistencia económica, financiera, jurídica y técnica, para la gestión de la movilidad, política del transporte y gestión de la infraestructura a través de una planeación participativa que comprende simultáneamente la movilidad, el medio ambiente y la organización territorial, y fijan reglas financieras a la cooperación entre el Estado y las comunidades territoriales (Lupano y Sánchez, 2009).

En contraste, en las ciudades latinoamericanas, las principales decisiones al respecto se han enfocado a dos tipos de soluciones simultáneas: 1) la ampliación de la capacidad vial para los automóviles, construyendo y ampliando avenidas y autopistas, y 2) la ampliación o mejora de los sistemas de transporte masivo, incluyendo algunos novedosos como metros de superficie o sistemas combinados. Pero como consecuencia de ser concurrentes, se potencia la congestión futura, y las vías para automóviles particulares y el transporte masivo se entorpecen mutuamente (Lupano y Sánchez, 2009).

En Buenos Aires, el resultado de la dinámica urbana fue la degradación del transporte público, hubo una mínima respuesta de nivel operativo en los sistemas de transporte por parte del estado, siguiendo el paradigma tradicional de expandir la oferta de infraestructura vial a través de la construcción y ampliación de autopistas urbanas y avenidas. Esta región metropolitana, así como México D.F., São Paulo y Santiago, fueron casos regionales emblemáticos de expansión y modernización vial, resultando en un balance decepcionante con la reiteración de los problemas iniciales cuyas consecuencias fueron la creación de nuevos tráficos motorizados que ocupan el nuevo espacio vial, incremento de la congestión en el perímetro urbano, la creación de nuevos desarrollos periféricos que consolidan la migración residencial; aumento de las distancias y 
duración de los viajes, con más consumo de combustible y emisión de contaminantes; y nueva saturación de los accesos urbanos en horas pico (Lupano y Sánchez, 2009).

Las presiones políticas para ampliar la infraestructura vial continúan a pesar de los resultados que no han resuelto la congestión urbana, por ello las soluciones basadas en el incremento de la oferta de infraestructura han llevado a soluciones que no son sustentables. Sin embargo se ha revalorizado el impacto y relevancia de las redes de transporte público, que en el contexto regional requiere fuertes inversiones en los sistemas para mejorar sustancialmente la calidad de los servicios, y la integración modal de las redes con mayor conexión física e institucional, para lograr mayor fluidez en los traslados, que tienda a la conformación de sistemas integrados de transporte masivo. Diversas experiencias en este sentido pueden tomarse como ejemplo, destacando los sistemas BRT (sistemas de bus rápido) que aparecieron en 1972 en Curitiba, posteriormente en Quito, y expandiéndose a partir del 2000 al "Transmilenio" de Bogotá, el sistema "Interligado" de São Paulo, Brasil en 2003; el BRT de México D.F. en 2005, diseñado para complementar al metro; el ramal de la ciudad de Pereira en Colombia; los casos de Guayaquil en 2006 y Guatemala en 2007 (Lupano y Sánchez, 2009).

En general, desde el punto de vista técnico la innovación radica en la jerarquización del modo vial tradicional, al transformarlo en una alternativa masiva mediante la utilización de buses de gran capacidad y múltiples puertas; acceso al servicio en estaciones dedicadas a nivel, donde se paga el ticket antes de abordar; control centralizado, con tecnologías modernas de monitoreo e información permanente a los pasajeros. Pero esencialmente se facilita la racionalización del espacio vial urbano al reservar carriles de circulación a lo largo de ejes troncales, con un alivio inmediato de la congestión del tráfico.

Los impactos generales han sido muy positivos en varias dimensiones: en primer lugar por la mayor eficiencia general del transporte público en términos de espacio urbano, pues un bus BRT moviliza 160 pasajeros, quienes demandarían la infraestructura vial necesaria para 114 automóviles (estándar de 1,4 por vehículo); en segundo lugar, mayor acceso a la movilidad urbana de sectores sociales con diversas limitaciones de ingresos, género, edad y discapacidad. Un aspecto relevante y no muy difundido consiste en que los mecanismos centralizados de control y monitoreo de los sistemas BRT han supuesto claras mejoras en la prevención de delitos contra la vida y propiedad (Lupano y Sánchez, 2009).

Una solución indirecta que ha surgido con enfoque de mejorar la movilidad en las ciudades es el concepto de teletrabajo. Verano, Suárez y Sosa (2014) han observado que el tema no está todavía en los planes de las empresas o de movilidad urbana, y solo se menciona como una opción que puede resultar útil. Estos autores precisan que el teletrabajo puede no ser siempre la mejor alternativa pues no todas las actividades pueden ser sustituidas de manera virtual, como los servicios de jardinería, limpieza o reparación de vehículos; en otros casos puede hacerse en teoría pero sus costos o dificultades lo hacen inviable, como las teleconferencias cuando las empresas no cuentan con redes digitales eficientes. Además puede ser visto como un obstáculo al progreso profesional en una empresa por falta de interacción directa con los niveles superiores. También hay consideraciones personales que no se pueden obtener con teletrabajo, como el repaso de plan de acción diario durante el recorrido, escuchar música o el disponer de un buen vehículo. Pero por otro lado, sí se ha encontrado una reducción de viajes y distancias de recorrido al implementarlo, además de los beneficios ambientales por reducción de ruido y emisiones, y desde luego menor congestión y accidentes viales. Sin embargo no hay suficientes antecedentes históricos, de modo que los datos no son plenamente concluyentes y no estudian los posibles efectos de rebote en los desplazamientos dados por el cambio de domicilio o hábitos de los trabajadores o la creación de ciertos servicios en las periferias que generen nuevas necesidades de transporte para el suministro de productos para satisfacerlas. 
En forma general, Thomson y Bull (2002) aclaran que la congestión es inevitable y es mejor controlarla dentro de ciertos límites, pues tratar de eliminarla conlleva altos costos por el desvío de usuarios a otras vialidades, medios u horarios de transporte, los provocados por la supresión de viajes y los que implica la ampliación de la capacidad vial. Estos costos pueden ser superiores a los causados por niveles moderados de congestión.

\section{La movilidad en las políticas públicas}

Como elemento constitutivo de la dinámica urbana, la movilidad es la base de políticas públicas enfocadas en la mejora de sus características, especialmente en las ciudades del mundo en desarrollo para los pobres y grupos vulnerables, lo cual forma parte de documentos de alcance tan amplio como los Objetivos de Desarrollo del Milenio establecidos por la ONU (Pardo, 2010). En México el Plan Nacional de Desarrollo 20132018 establece como estrategias de crecimiento y movilidad social, a la movilidad de capitales, integración productiva, la movilidad segura de las personas y la atracción de talento e inversión. En cuanto a la movilidad urbana, reconoce la necesidad de mejorarla dadas la alta tasa de motorización y expansión urbana, y la deficiente infraestructura de transporte urbano masivo (Gobierno de la República, 2013).

Las políticas de movilidad se abordan desde variados enfoques: el urbanismo centrado en la calidad de vida de los ciudadanos, el transporte económicamente eficiente y ambientalmente sustentable, la visión de los gobiernos, de los proveedores de obras y servicios, de la universidad, de la banca y las instituciones internacionales (Lupano y Sánchez, 2009). Las ciudades con modos de transporte que funcionen como sistemas integrados tienen mejores probabilidades de prosperar como centros de comercio, industria, educación, turismo y servicios, y existen en todo el mundo redes y organizaciones que promueven el transporte urbano sostenible (Pardo, 2010), pero los modelos urbanos de movilidad sostenible deben apoyarse en el planeamiento territorial para identificar los patrones de localización e intensidad de usos del suelo, lo que lleva a conocer las características de la demanda y tipos de transporte adecuados (Cardozo, Gutiérrez y García Palomares, 2010).

Debido a las externalidades, en el análisis económico del transporte urbano no se pueden asignar todos los costos relevantes, de modo que se requiere una nueva generación de políticas orientadas a la gestión y regulación de la demanda de espacio vial urbano, en especial para el transporte motorizado particular porque la expansión y mejora de la infraestructura de transporte público por sí misma, a pesar de ser imprescindible no será suficiente para llegar a niveles aceptables de congestión y contaminación ambiental (Lupano y Sánchez, 2009).

Experiencias en esta dirección pueden observarse en la aplicación de peajes urbanos en Londres y Singapur, en este último caso se han incorporado además tecnologías innovadoras basadas en la instalación obligatoria de chips "inteligentes" en todo el parque automotriz. Otras alternativas incluyen la gestión del estacionamiento en áreas específicas y por horas del día, reducciones de velocidad, etc. Algunas opciones hacia el transporte público y otros modos no contaminantes son la reasignación de carriles y pistas y su reserva para buses y ciclovías, la redistribución de fases de semáforos a favor de medios colectivos y no motorizados, etc. (Lupano y Sánchez, 2009).

El desarrollo de soluciones de movilidad debe considerar de manera explícita la atención a personas con movilidad personal reducida, como son los ancianos, mujeres embarazadas o personas con capacidades diferentes. Entre las medidas, Pardo (2010) menciona la eliminación de barreras físicas mediante rampas, elevadores y plataformas para acceso, o sillas de ruedas en posición de espera, y las recientes regulaciones que se han establecido al respecto en varias ciudades para los proyectos de construcción, incluyendo edificios, caminos, puentes, pasos peatonales, estaciones de metro y tren, así 
como sitios turísticos. En las ciudades de México y Río de Janeiro, y algunas de India, por ejemplo, se han dispuesto carritos exclusivos para mujeres en autobuses o trenes para su mayor comodidad; otras soluciones consisten en tarifas de transporte para viajes múltiples o por un tiempo determinado, como se hace en Hong Kong y muchas otras ciudades; subsidios para incrementar la posibilidad de uso, como en el BRT de Bogotá, en donde el costo del viaje sencillo es igual para todos los viajes, de modo que viajes más largos de la población periférica de escasos recursos, es compensado con el pago de los viajes cortos de la población de altos ingresos que se mueve en la zona centro.

Se pueden resumir las experiencias exitosas en: procesos explícitos de desconcentración de las decisiones mediante autoridades locales autónomas con recursos adecuados y competencia plena sobre todos los modos de transporte, lo que implica fuertes liderazgos; enfoques integrales de mediano plazo que incluyen aspectos ambientales y redistributivos con la participación de usuarios y actores locales en el diseño; recursos fiscales aplicables solo a programas de transporte; un marco integrado del transporte público, que habilita subsidios modales cruzados (en la medida en que los ingresos globales del sistema cubran todos sus costos, incluyendo infraestructura, daños ambientales, siniestralidad, etc.), lo que permite a su vez una progresiva expansión de mecanismos de integración tarifaria intermodal; cooperación público-privada, que en algunos casos ha derivado en una expansión significativa de las concesiones de operación con el surgimiento de nuevos segmentos empresarios. Pero a nivel regional, los esquemas de participación privada y su estabilidad normativa requieren ser perfeccionados (Lupano y Sánchez, 2009).

También es fundamental el monitoreo de los patrones de movilidad para asegurar la sustentabilidad del desarrollo en las ciudades, lo que implica establecer indicadores y superar los retos que presenta la diversidad de ciudades, desde su misma definición como concepto considerando sus límites y distribución de población. Los indicadores de medio ambiente y sostenibilidad urbana contemplan los de movilidad y transporte (Salado García et al., 2006). Poelman y Dijkstra (2015) proponen un índice normalizado de sostenibilidad en el transporte, diseñado para Europa en donde se consideran como objetivos: la reducción de necesidad de viajes a través de compras por internet, teletrabajo y el uso de tecnologías de la información; el fomento a los cambios de modos de transporte a través de evaluación de las políticas en el tema; reducción de distancias de viajes a través de la planeación urbana y de uso del suelo; y la promoción de mayores eficiencias en los sistemas de transporte. Los indicadores incluyen los aspectos de presupuesto, planeación urbana, seguridad, tiempo, salud y medio ambiente, y sociedad (Poelman y Dijkstra, 2015; Zito y Salvo, 2011). Se reconoce que los indicadores de movilidad sostenible son de difícil operatividad por referirse a un concepto vago, y es más fácil establecerlos para un modelo de transporte sostenible que incluyan por ejemplo la dotación/calidad, interconectividad e intermodalidad (Salado García et al., 2006).

Sin embargo, no debe perderse de vista que la preferencia de los automovilistas por el uso del vehículo particular está arraigada en América Latina, de modo que la mejora en los sistemas de transporte público tiene más probabilidades de atraer a usuarios de otros modos de transporte que a los automovilistas. Para captar a estos últimos se tendría que ofrecer una opción con mejores características, tanto en sus prestaciones de comodidad como en aspectos objetivos dados por tarifa, tiempo de viaje y frecuencia (Thomson y Bull, 2002).

\section{Resultados y discusión}

La movilidad es un concepto que abarca toda una realidad social actual, al punto que se ha definido como el mayor desafío para la vida urbana contemporánea, pues se manifiesta desde el ámbito mundial hasta el espacio más específico de estudio a nivel 
local. También tiene una multiplicidad de elementos configuradores, algunos de los cuales son a la vez causa y efecto, aunque en el diseño de las soluciones técnicas normalmente se encuentran implícitas las medidas para mejorar la movilidad, al mismo tiempo en que se reduce la congestión.

Algunas respuestas ya consideran criterios de sustentabilidad en donde se incluyen medidas de control de emisiones, reducción de ruido y en general menor contaminación, así como aspectos de equidad social a través de mejorar la accesibilidad al transporte público tanto en las unidades, como en los paraderos, y acercando la cobertura del servicio a las zonas marginales. Otro enfoque de la equidad social se ha aplicado en el diseño de los planes de ordenamiento urbano en los que se redistribuyen los espacios sociales o se dan facilidades para el traslado de las clases de menores ingresos a los centros urbanos.

A través del acercamiento al estado del arte de la movilidad, se pueden identificar los siguientes elementos configuradores:

» La migración como causa de movilidad, y efecto de la globalización económica, tanto internacional como local al interior de los países, con todas sus causales que se clasifican en económicas, familiares, de educación, estilo de vida o por migración forzada. Una manifestación con características específicas la constituye el caso de los refugiados.

» La urbanización creciente, principalmente en Latinoamérica, produciendo demandas de movilidad que se convierte en factor de desarrollo político, económico y sociocultural por sí misma, lo que se manifiesta en el crecimiento de los tráficos y la motorización.

» Los espacios sociales del territorio, destacando aquellos donde se producen las principales transformaciones sociales y urbanas.

"La infraestructura material existente para la movilidad, con sus cuatro características generales: que no siempre es evidente; que en su estudio también deben considerarse sus arreglos, tecnologías y relaciones, no solo sus características físicas; que sus límites no son iguales a los de una demarcación geopolítica; y los riesgos de fallo que implica su complejidad.

" La necesidad imprescindible de sostenibilidad y seguridad en las ciudades, lo que incluye aspectos como reducción de las desigualdades sociales principalmente en la accesibilidad al transporte, que requiere una óptima integración ambiental para lograr resultados más válidos.

》Los costos de la movilidad, tanto privados como sociales, indirectos o externalidades, que también deben estar incluidas en cualquier análisis ambiental.

" La congestión, como un fenómeno que representa la contraparte de la movilidad, y es el principal problema derivado del crecimiento de los flujos. Debe estudiarse en sus aspectos de tránsito, económicos y de gestión.

" Las políticas públicas, que apoyándose entre otras en el planeamiento urbano, deben considerar todos los aspectos anteriores y son la base para la aplicación operativa en materia de movilidad.

Al final, se puede identificar que el objetivo de los estudios y soluciones en materia de movilidad, tiene como enfoques básicos: mejorar la calidad de vida de los habitantes, lograr la eficiencia en el transporte (como elemento catalizador, pues no puede ser un fin en sí mismo) y buscar la sostenibilidad de las ciudades. Pero a pesar de que estos tres están estrechamente relacionados, las políticas públicas no siempre los consideran de manera integral, y normalmente se establecen objetivos independientes que muchas veces resultan en estrategias parciales o incompletas en el mejor de los casos, pudiendo llegar al extremo de dar resultados contraproducentes, lo que se manifiesta en gestiones de gobierno que fracasan y estancamiento o retroceso en las condiciones de bienestar de la población. 
El análisis coincide con las posiciones que han propuesto Cruz-Zúñiga (2016) al identificar la migración como uno de los agentes de movilidad más importantes; Jordán, et al., (2003) al establecer la necesidad de una política de transporte; Vivas y Ribera (2007) quienes definen los espacios sociales como creadores de formas de vida como reflejo de la movilidad; Cabrera-Arana, Velásquez-Osorio, Orozco-Arbeláez (2015) al plantear como dimensiones básicas de ésta el ser segura y sostenible; Lupano y Sánchez (2009) cuando señalan la necesidad de identificar las externalidades en el ánalisis de costos; o Thomson y Bull (2002) cuando establecen todo el análisis de la teoría de la congestión.

\section{Conclusiones}

Con el análisis realizado, se han podido identificar los elementos que configuran la movilidad, y la relación estrecha que deben tener las propuestas técnicas que se traduzcan en políticas públicas para mejorar la calidad de vida de los habitantes, la cual depende íntimamente de la sostenibilidad urbana, teniendo como elemento de unión la eficiencia en el transporte.

Por lo tanto, en el ámbito local, es posible establecer que el diseño de un modelo de movilidad para un centro urbano específico debe considerar la integración de todos los elementos que la generan y configuran: las motivaciones de las personas, las tendencias de crecimiento urbano y del parque vehicular, la identificación de los espacios sociales del territorio, las características de la infraestructura física y su integración, la evaluación ambiental y realidad de desigualdades sociales, así como los costos involucrados, tanto privados como sociales o externalidades. A partir de ese análisis deben diseñarse políticas públicas que se traduzcan entre otras cosas, en planes de ordenamiento urbano que cuenten con los medios para su monitoreo y evaluación, dentro de lo cual la congestión es una variable fundamental. El objetivo final debe ser mejorar la calidad de vida, de modo que es necesario generar los elementos de medición que permitan establecer la correlación entre ésta y la movilidad. 


\section{Q Bibliografía}

"Boschmann, E. y Kwan, M. P. (2008). Toward Socially Sustainable Urban Transportation: Progress and Potentials, International Journal of Sustainable Transportation, 2, 138-157.

»Bull, A. (compilador) (2003). Congestión de tránsito, el problema y cómo enfrentarlo, Cuadernos de la CEPAL, 87. Santiago de Chile.

"Cabrera-Arana, G., Velásquez-Osorio, N. y Orozco-Arbeláez, A. (2015). Movilidad: Aporte para su discusión. Revista Facultad Nacional de Salud Pública, 33 (3), 429-434.

"Cardozo, O., Da Silva, C. y Gómez, É. (2015). Modelos para la estimación de la demanda en transporte público. En: Gustavo D. Buzai, Graciela Cacace, Luis Humacata, Sonia L. Lanzelotti (compiladores), Teoría y métodos de la Geografía Cuantitativa. Libro 1. Por una geografía de lo real. Primera edición. MCA Libros. Buenos Aires, 175-193.

»Cardozo, O., Gutiérrez, J. y García Palomares, J. (2010). Influencia de la morfología urbana en la demanda de transporte público: análisis mediante SIG y modelos de regresión múltiple, GeoFocus, Revista Internacional de Ciencia y tecnología de la Información Geográfica, 10, 82-102.

»Castles, S. (2014). Las fuerzas tras la migración global. Revista Mexicana de Ciencias Políticas y Sociales. LIX (220), 235-260.

»Chaparro, I. (2002). Evaluación del impacto socio económico del transporte urbano en la ciudad de Bogotá. El caso del sistema de transporte masivo, Transmilenio. Serie Recursos Naturales e Infraestructura, 48. Publicación de las Naciones Unidas, Edición: Nueva York, EUA, Impresión: Santiago de Chile, Chile.

"Cruz-Zúñiga, P. (2016). Movilidad humana, retos y desafíos para la convivencia local. ResearchGate. Congreso Internacional Laudato Si de Ecología Integral y Medio Ambiente, organizado por la Universidad Católica San Antonio de Murcia, 5-3.

»Da Cunha, J. y Rodríguez-Vignoli, J. (2009). Crecimiento urbano y movilidad en América Latina. Revista Latinoamericana de Población, 3 (4-5), 27-64.

» Farber, Steven et al. (2014). Assessing social equity in distance based transit fares using a model of travel behavior, Elsevier, Transportation Research Policy and Practice Part A, 67, 291-303.

»Gobierno de la República (2013). Plan Nacional de Desarrollo 2013 - 2018. Diario Oficial de la Federación, segunda sección, 20-05, Ciudad de México, México.

»Islas-Rivera, V., Rivera-Trujillo, C. y Torres-Vargas, G. (2002). Estudio de la demanda de transporte. Publicación técnica, Instituto Mexicano del Transporte, 213, San Fandila, Pedro Escobedo, Qro, México.

" Jordán, R. (2003). Ciudad y desarrollo en América Latina y el Caribe. En: Jordán Ricardo y Simioni, Daniela (Compiladores), Gestión urbana para el desarrollo sostenible en América Latina y el Caribe. Publicación de las Naciones Unidas, 75, Edición: Nueva York, EUA, Impresión: Santiago de Chile, 43-70.

» Korstanje, M. (2013). Homo Mobilis. La nueva era de la movilidad. Alteridades, 23 (46), 138-140. 
» Lange Valdés, C. (2011). Dimensiones culturales de la movilidad urbana. Revista INVI, 26 (71), 87-106.

"Litman, T. (2017). Land use impacts on Transport. How Land Use Factors affect travel behavior. Victoria Transport Policy Institute. Canada.

»Lupano, J., Sánchez, R. (2009). Políticas de movilidad urbana e infraestructura urbana del transporte. Colección Documento de proyecto, Publicación de las Naciones Unidas, Febrero, Edición: Nueva York, EUA, Impresión: Santiago de Chile.

" Marcu, S. (2016). (re)pensar la movilidad humana en el contexto fronterizo de la unión europea. Evidencias empíricas de los europeos del este en España. ResearchGate. Spanish National Research Council. Conference paper, XIV Congreso Nacional de Población, AGE Sevilla 2014, 10-12 Septiembre. <https:// www.researchgate.net/ publication/ 301789524>.

"Mattos, C. A. de (2006). Modernización capitalista y transformación metropolitana en América Latina: cinco tendencias constitutivas. En: América Latina: cidade, campo e turismo. Amalia Inés Geraiges de Lemos, Mónica Arroyo, María Laura Silveira. CLACSO, Consejo Latinoamericano de Ciencias Sociales, San Pablo. Diciembre 2006, http://bibliotecavirtual.clacso.org.ar/ar/libros/ edicion/lemos/ ozmattos.pdf.

» Medina, S. (2012). Transformando la movilidad urbana en México.Hacia ciudades accesibles con menor uso del automóvil. Instituto de Políticas para el Transporte y Desarrollo. Distrito Federal, México.

» Mignot, D., Aguiléra, A., Bloy, D., Caubel, D., Madre, JL. (2010). Formas urbanas, movilidad y segregación. Urban Public Economics Review, 12, 73-104.

» Muñiz, I., Rojas, C., Busuldu, C., García, A., Filipe, M., Quintana, M. (2016). Forma urbana y Huella Ecológica en el Área Metropolitana de Concepción (Chile), Eure. Revista latinoamericana de estudios urbano regionales, 42 (127), 209-230.

»Pardo, C. (2010). Sustainable Urban Transport. En: Shanghai Manual, A Guide for Sustainable Urban Development in the 21st. Century. United Nations, Bureau International des Expositions, Shanghai 2010 World Exposition Executive Committee, Edición: Nueva York, EUA.

" Pérez Negrete, M. (2015). Sobre movilidades e inmovilidades: un acercamiento etnográfico a la construcción de la desigualdad en la ciudad de México. Espacialidades. Revista de temas contemporáneos sobre lugares, política y cultura, 5 (2), 148-175.

»Poelman, H., Dijkstra, L. (2015). Measuring access to public transport in European cities. Working papers. WP/01/2015, European Commission, Bruselas, Bélgica.

» Reyes-Tovar, M., Martínez-Ruiz, D. (2015). La configuración identitaria en los territorios de migrantes internacionales. Península, X (2), 117-133.

» Roa, H., Rojas, C., Carrasco, J., Tudela, A. (2013). Movilidad urbana e indicadores de exclusión social del sistema de transporte: evidencia en una ciudad intermedia chilena. Revista Transporte y Territorio, 8, 45-64.

» Rojas, C., Páez, A., Barbosa, O., Carrasco, J. (2016). Accessibility to urban green spaces in Chilean cities using adaptive thresholds. Journal of Transport Geography, 57, 227-240.

» Rojas, C., Plata, W., Valdebenito, P., Muñiz, I., De La Fuente, H. (2014). La Dinámica de expansión urbana del Área Metropolitana de Concepción. Metropolizaciones, ResearchGate, pp. $39-56$ <https://www.researchgate. 
net/publication/281723086_La_Dinamica_ de_ expansion_urbana_del_ Area_Metropolitana_de_Concepcion_Metropolizaciones_Colombia_-Chile_ Experiencias_de_Bogota_Medellin_Santiago_y_Concepcion>.

» Salado García, M., Díaz Muñoz, M., Bosque Sendra, J., Carvalho Cantergiani, C., Rojas Quezada, C., Jiménez Gigante, F., Barnett, I., Fernández, C., Muñoz Rueda, C. (2015). Movilidad sostenible y sig. Propuesta de evaluación del transporte público en Alcalá de Henares, Proyecto "Planificación y desarrollo sostenible. Notas sobre la ciudad”, Ministerio Ciencia y Tecnología, Alcalá de Henares (Madrid), 1777-1794.

»Santos, M. (1995). Metamorfosis del espacio habitado, traducción: Gloria María Vargas López de Mesa. Oikos tau, Primera edición, Impreso en España.

»Shaohua, Z. (2005). Migración de la mano de obra rural en China: desafíos para las políticas, Colección Políticas Sociales / 10, UNESCO. SHS-2005/WS/25 - cld // 21550, Impreso en Francia.

"Sheller, M., Urry, J. (2006). The new mobilities paradigm, Environment and Planning A, 38, 207-226.

"Soria Lara, J., Valenzuela-Montes, L. (2015). Dimensiones relevantes para la evaluación ambiental proactiva de la movilidad urbana. Investigaciones Geográficas, Boletín del Instituto de Geografía, 87, 5-24.

»Thomson, I., Bull, A. (2002). La congestión del tránsito urbano: causas y consecuencias económicas y sociales. Revista de la CEPAL, 76, 109-121.

»United Nations (2016). International Migration Report 2015: Highlights, Department of Economic and Social Affairs, Population Division (ST/ESA/ SER.A/375).

»Verano-Tacoronte, D., Suárez-Falcón, H., Sosa-Cabrera, S. (2014). El teletrabajo y la mejora de la movilidad en las ciudades. Investigaciones Europeas de Dirección y Economía de la Empresa, 20, 41-46.

»Vich, G., Delclòs, X., Miralles-Guasch, C. (2015). La proximidad residencial al transporte público. Un ejemplo a partir de la Encuesta de Movilidad de la UAB. Presentación: International Conference on Regional Science: Innovation and geographical spillovers: New Approaches and evidence. Facultad de Economía y Empresa de la Universitat Rovira i Virgili. 18-20 Noviembre, Reus, España.

»Vivas, P., Ribera-Fumaz, R. (2007). Ciudades, movilidad y tecnología: hacia la Barcelona móvil. UOC Papers, revista sobre la sociedad del conocimiento, 5, 14-22.

»Zapata-Barrero, R. (2012). Teoría política de la frontera y la movilidad humana. Revista Española de Ciencia Política, 29, 39-66.

»Zito, P., Salvo, G. (2011). Toward an urban transport sustainability index: an European comparison. European Transport Research Review, 3 (4), 179-195.

\section{Gerardo Alonso Romero / alonsogr22@hotmail.com}

Estudiante en el programa Doctoral en Proyectos, Centro Panamericano de Estudios Superiores. Realizó sus estudios de licenciatura de ingeniería civil en la Universidad de Guanajuato y la maestría en ingeniería de vías terrestres en la Universidad Autónoma de Querétaro. Actualmente es consultor independiente en estudios de geotecnia y control de calidad de materiales para vías terrestres. 


\section{Diosey Ramón Lugo-Morin / diosey.lugo@cepes.edu.mx}

Ingeniero Agrónomo. Doctor en Ciencias en Estrategias para el Desarrollo Agrícola Regional por el Colegio de Postgraduados, México. Postdoctorado por el Centro de Estudios Avanzados de la Universidad Nacional de Córdoba, Argentina. Actividad profesional: Consultor, ProfesorInvestigador en Desarrollo Sustentable y Profesor-Tutor en el Centro Panamericano de Estudios Superiores. Conferencista y ponente en congresos internacionales en México, Venezuela, Ecuador, Portugal, Brasil, España y Argentina. Miembro del Sistema Nacional de Investigadores Nivel II. 